\title{
Green Biosynthesis of Silver Nanoparticles Using Gallium aparine Green Part Extract and Anti-skin Cancer Activity.
}

\author{
Omar Hasnawi Hamdi ${ }^{1}$, Shurook M.K. Saadedin ${ }^{2}$, Iqbal Harbi Mohammed AL_ZAIDI ${ }^{3}$ \\ ${ }^{1}$ Researcher/Institute of Genetic Engineering and Biotechnology for Postgraduate Studies, University of Baghdad, \\ Iraq, ${ }^{2}$ Asst. Prof. Dr. Institute of Genetic Engineering and Biotechnology for Postgraduate Studies/University of \\ Baghdad/Iraq, ${ }^{3}$ Head of Biology/Ministry of Agriculture/Horticulture Office/Research Department/Iraq
}

\begin{abstract}
Background: Galium aparine has a long history of use as an alternative medicine and is still used widely by modern herbalists. It is a fabulous diuretic that is often taken to treat skin problems. It treats many problems such as seborrhoea, eczema, psoriasis. It also acts as a great detoxifying agent in life-threatening ailments like cancer. Skin cancer is the most common type of cancer in light skinned populations around the world.

Aim: The aim of the study was to evaluate the anticancer efficacy of greensynthesised silver nanoparticles (AgNPs) of Gallium aparine extract.

Method: The green part of the plant G.aparne extracted with ethanol 70\%, then divided into four fractions to prepare stable AgNPs .

Results: Several tests were performed to examine the extracts and AgNPs, including SEM,FTIR and UVVS. Scanning electron microscope(SEM)micrographs showed that the diameters range of AgNPs formed were from 35-110 nm.Fourier transform infrared (FTIR) shows that there were two functional groups, the aromatic $(\mathrm{C}=\mathrm{C})$ and hydroxyl $(-\mathrm{OH})$, groups may be involve in the fabrication of AgNPs. UV-VS shows that there were a peaks at $298,448,534,606,648$, for nanoscale petroleum ether extract. These peaks may beindicate the synthesis of AgNPs. Different concentrations $(6.225-400 \mu \mathrm{g} / \mathrm{ml})$, of petroleum ether extract and its green AgNPswere tested as anti-skin cancer, the nanoparticles had appositive effect against cancer, the IC50 for the petroleum ether extract was 730.2 and 116.5 of normal cell line (WRL 68) and cancer cell line (A375), respectively,while the IC50 for the AgNPs of Gallium aparine extract was 294.4 and 77.03 of normal cell line (WRL 68) and cancer cell line (A375)respectively.
\end{abstract}

Discussion: This indicates that the G. aparine extract is a good biological carrier for synthesizing silver nanoparticles which has potential for various biomedical and pharmaceutical applications.

Conclusion: AgNPs have been successfully synthesized using $G$. aparian extract, The nanoparticles have shown good anticancer activity towards human skin cancer cells.

Keywords: Gallium aparine, AgNPs, Green Synthesis, WRL 68, A375.

\section{Introduction}

Galium aparine has a long history of use as an

\section{Corresponding Author:}

Shurook M.K. Saadedin

Asst. Prof. Dr. Institute of Genetic Engineering and

Biotechnology for Postgraduate Studies/University of

Baghdad/Iraq

e-mail: ssaadedin@gmail.com alternative medicine and is still used widely by modern herbalists as diuretic and to treat skin problems. It treats many problems such as seborrhoea, eczema, psoriasis, wounds, skin problems and ulcers. It also acts as a great detoxifying agent. The infusion is used to treat liver, bladder and urinary problems and cancer ${ }^{(1)}$.

Skin cancer is the most common type of cancer in light skinned populations around the world ${ }^{(2)}$. Skin cancers are mainly divided into melanoma, 
and nonmelanoma skin cancers (NMSCs), the latter including basal and squamous cell carcinomas (BCC and SCC, respectively). Melanoma is responsible for most of the cancer related mortalities, and NMSCs are typically described as having a more benign course with locally aggressive features. Nevertheless, they represent "the most common type" of cancer in humans and they can result in significant disfigurement, leading to adverse physical and psychological consequences for the affected patients ${ }^{(3)}$.

Nanotechnology is the science that deals with the processes that occur at a molecular level and of nano length scale size which involves the tailoring of materials at the atomic level to attain unique properties that can be suitably manipulated for the desired applications ${ }^{(4)}$.

Nanoparticles, usually ranging in dimension from 1-100 nanometers $(\mathrm{nm})$, have properties unique from their bulk equivalent and are related to the decrease in the dimensions of the materials to the atomic level ${ }^{(5)}$. Nanosilver has many medical applications including diagnosis, treatment, drug delivery, coating tools and medical devices ${ }^{(6)}$. This study was aimed to test the effect of petroleum ether synthesised nanoparticlesof G.aparine on skin cancer in vitro.

\section{Materials and Method}

Plant Materials: The green parts of Galium aparine plant were collected in February 2019 from AlJadriya University site, Baghdad. The plants were dried in shadow and then grinded by electric grinder to a fine powder and stored in an airtight container until used.

Extraction: The extract was prepared according to the method of Ozaki(7) with some modification. The extract was prepared by dissolving $50 \mathrm{gm}$ of plant materials with $500 \mathrm{ml}$ of ethanol (70\%). The extract is placed in a flask and covered with aluminum foil. It was placed on a hot plate with a stirrer without heat for 6 hours, filtered after that then the ethanol was removed through rotary evaporator and the extracted material wasdivided into four fractions of petroleum ether, ethyl ether and butanol, and the remainder was the fraction dissolved in water (aqueous)using separatory funnel. The extraction materials were added according to the volume-to-volume ratio (1:5.ethanol: solvent). It was repeated three times for each fraction to obtain the largest amount of the extract, then in each stage the petroleum ether, ethyl ether and butanol were disposed by rotary evaporator and water by means of the oven at a temperature of $40^{\circ} \mathrm{C}$.

Biosynthesis of AgNPs: The procedure of AgNPs synthesis was modified from Awwad ${ }^{(8)}$. The nanoscale extract (petroleum ether, aqueous) was prepared by dissolving $40 \mathrm{mg}$ of the extract in $10 \mathrm{~mL}$ of deionized water and $1 \mathrm{~mL}$ tween 20 . Silver nitrate was prepared in three concentrations ( 1 molar ( $0.0051 \mathrm{~g} \mathrm{AgNo3}), 2$ molar (0.0102 $\mathrm{g} \mathrm{AgNo3}), 4$ molar (0.0244 g AgNo3)) in 29 $\mathrm{ml}$ of water. The extract with silver nitrate in different molarity was placed in a beaker on the hot plate with magnetic stirring at a temperature of $40^{\circ} \mathrm{C}$, until the color changed to reddish brown which indicates the biosynthesis of the AgNPs .

\section{Characterization of AgNPs:}

Scanning electron microscope (SEM): A scanning electron microscope (SEM, Shimadzu) was employed to analyze the morphology of the nanoparticles that were formed. The Morphological characterization of the samples was done using mira3 Tescan for SEM analysis. The samples were dispersed on a slide and then coated with platinum in an auto fine coater. After that, the material was subjected to analysis ${ }^{(9)}$.

Fourier Transform Infra-Red (FTIR): Identification of possible biomolecules of $G$. aparine responsible for the reduction and stabilization of silver nanoparticles was recorded using (Bruker VERTEX-70) FT-IR spectrophotometer in the range of $3500-1000^{(10)}$. and compared with standard chart. The characterization of functional groups on the surface of AgNPs by plant extract was investigated by FTIR analysis and the spectra was scanned in the range of 4000--400 cm-range at a resolution of $4 \mathrm{~cm}$. The sample used in this analysis was in their native liquid form during the analysis ${ }^{(8)}$.

UV-visible spectroscopy: Absorbance spectra of AgNPs solution were measured by UV - VIS double beam spectrophotometers (Shimadzu). All spectra were measured at room temperature in a quartz cell with 1 $\mathrm{cm}$ optical path. Deionized distilled water was used as a blank. The absorption was taken from (200-800nm). Some samples became too concentrated and they were diluted 1:10 in deionized water ${ }^{(11)}$.

\section{Cell Line:}

A375Cell Line: Cultures of human malignant melanoma (A375 cell line, ATCC number CRL-1619) 
were examined at (passage 5) were grown in the supplemented culture medium consisting of Dulbecco's modified Eagle's medium with L-glutamine and phenol red (DMEM; Sigma-Aldrich, D5796), supplemented with 10\% heat-inactivated fetal bovine serum (FBS; Biochrom GmbH, S0615), 1\% penicillin-streptomycin mixture (Sigma-Aldrich, P4333), and 1\% Amphotericin B (Sigma-Aldrich, A2942). Cell cultures were incubated at $37^{\circ} \mathrm{C}$ in $5 \% \mathrm{CO}_{2}$. When confluent, cells were washed three times with DPBS, detached using TrypLE Express ${ }^{\mathrm{TM}}$ (Gibco Invitrogen, INV 12605028, 4 to $5 \mathrm{ml} / 175 \mathrm{~cm}^{2}$ tissue culture flask), and seeded at 4 $\times 10^{4}$ cells $/ \mathrm{ml}$ in $3.3 \mathrm{~cm}^{2}$ diameter tissue culture dishes which contained $3 \mathrm{ml}$ of supplemented DMEM and were so further incubated for $24 \mathrm{hrs}$ to allow for attachment.

WRL 68 Cell Line: The human liver cell line WRL 68 exhibits morphology similar to that of hepatocytes and liver primary cultures. Cells have been shown to secrete albumin and alpha-fetoprotein and express liverspecific enzymes, such as alanine aminotransferase ${ }^{(12)}$.

MTT Cytotoxicity Assay: A confluent A375, WRL 68 Cell Line monolayer with the cell density of $4 \times 10^{4}$ cells/well was seeded in 96- well plates. After incubation at $37^{\circ} \mathrm{C}$ in a $5 \% \mathrm{CO} 2$ incubator for $24 \mathrm{~h}, 100 \mu \mathrm{L}$ of each two-fold serially diluted extract (concentrations ranging from $(6.250,12.5,25,50,100,200,400 \mathrm{mg} / \mathrm{mL}) \mu \mathrm{g} / \mathrm{mL})$ in maintenance medium (DMEM with $1 \% \mathrm{FBS}$ ) was added to the wells. Medium control (blank medium) and cell control (cells without extract treatment) were also incorporated in the same plates. The plates were incubated for another $72 \mathrm{~h}$ at $37{ }^{\circ} \mathrm{C}$ in a $5 \% \mathrm{CO} 2$ incubator and the cell viability was evaluated using the MTT colorimetric assay as described by Mosmann ${ }^{(13)}$ with some modifications. A $20 \mu \mathrm{L}$ of MTT solution (5 $\mathrm{mg} / \mathrm{mL}$ in phosphate buffered saline (PBS)) was pipetted into each well followed by a 3-hour incubation period at $37^{\circ} \mathrm{C}$ in the $5 \% \mathrm{CO} 2$ incubator. Seventy percent of the mixture was then removed and $150 \mu \mathrm{L}$ of dimethyl sulfoxide was added to the wells to dissolve the MTT formazan. The absorbance was determined at $575 \mathrm{~nm}$ using a microplatereader (Bio-rad, Germany). Results were obtained from three independent experiments.

\section{Results and Discussion}

Synthesis and Characterization of silver nanoparticles (AgNPs): Silver nanoparticles were prepared by the green method and characterized by using Scanning Electron Microscope (SEM), UV - VIS spectroscopy, Fourier transform infrared spectroscopy (FTIR) . The four extracts acted as a reducing agent, which reduces metallic silver to nanosilver and hence the color changed. The AgNPs extracts exhibit light brown color, this could be attributed to the of surface plasmon vibrations. $\mathrm{Ag} 2+$ ions of silver nitrate are found to be reduced to $\mathrm{Ag}^{\mathrm{o}}$ atoms ${ }^{(14)}$.Krithiga ${ }^{(15)}$ reported that the AgNPs exhibited striking colors, from colorless to yellowish brown.

\section{Scanning Electron Microscopy (SEM):} Scanning electron microscope was employed to analyze the sizes of petroleum ether and aqueous AgNPs table (1). SEM analysis shows that the G.aparnie plant has a tremendous capability to AgNPs which were uniformly distributed with an average size ranged from 61-86 and this agreed with ${ }^{(16)}$.

Table 1: Scanning Electron Microscopy (SEM) of petroleum ether and aqueous extracts $(1,2$, and 4 molar)

\begin{tabular}{|l|l|}
\hline Sample:B1 & \\
\hline Avg. Diameter:76.52 $\mathrm{nm}$ & $<=10 \%$ Diameter:45.00 nm \\
\hline$<=50 \%$ Diameter:75.00 nm & $<=90 \%$ Diameter: $100.00 \mathrm{~nm}$ \\
\hline Sample:B2 & \\
\hline Avg. Diameter:86.82 $\mathrm{nm}$ & $<=10 \%$ Diameter: $60.00 \mathrm{~nm}$ \\
\hline$<=50 \%$ Diameter:85.00 nm & $<=90 \%$ Diameter:105.00 nm \\
\hline Sample:B4 & \\
\hline Avg. Diameter:64.66 nm & $<=10 \%$ Diameter:35.00 nm \\
\hline$<=50 \%$ Diameter:65.00 nm & $<=90 \%$ Diameter: $85.00 \mathrm{~nm}$ \\
\hline Sample:E1 & \\
\hline Avg. Diameter:82.56 nm & $<=10 \%$ Diameter: $45.00 \mathrm{~nm}$ \\
\hline$<=50 \%$ Diameter:80.00 nm & $<=90 \%$ Diameter: $110.00 \mathrm{~nm}$ \\
\hline Sample:E2 & \\
\hline Avg. Diameter:61.50 nm & $<=10 \%$ Diameter: $45.00 \mathrm{~nm}$ \\
\hline$<=50 \%$ Diameter:60.00 nm & $<=90 \%$ Diameter:70.00 nm \\
\hline Sample:E4 & \\
\hline Avg. Diameter:66.71 nm & $<=10 \%$ Diameter: $40.00 \mathrm{~nm}$ \\
\hline$<=50 \%$ Diameter:65.00 nm & $<=90 \%$ Diameter: $85.00 \mathrm{~nm}$ \\
\hline
\end{tabular}

B1:1molar AgNo3 petroleum etherextract, B2:2molar AgNo3 petroleum etherextract, B4: 4 molar AgNo3 petroleum etherextract. E1:1molar $\mathrm{AgNo} 3$ aqueous extract, E2:2 molarAgNo3aqueous extract, $\mathbf{E} 4: 4$ molarAgNo3 aqueous extract.

The 4 molar AgNo3 petroleum ether was selected for the anticancer test and for further examination, because it had less than $65 \mathrm{~nm}$ average size table (1) and the best antioxidant capacity ${ }^{(17)}$. 
2. Visual observation and $U V$-vis spectral study: Formation and stability of prepared AgNPs in deionized water was approved by UV-Vis spectrophotometer during a range of 200-800 $\mathrm{nm}$ of wavelength. Figure (2) shows the UV-Vis spectrum collected from the reaction medium after one hour. As shown in Fig.2 A and $\mathrm{B}$, there were peak at 298,448, 534, 606, 648, for nanoscale petroleum ether extract, Fig. 2 B. All these peaks indicated the synthesis of $\mathrm{AgNPs}^{(18)}$. There were peaks at 462,624, 654 for Natural petroleum ether extract, Fig.2 A.

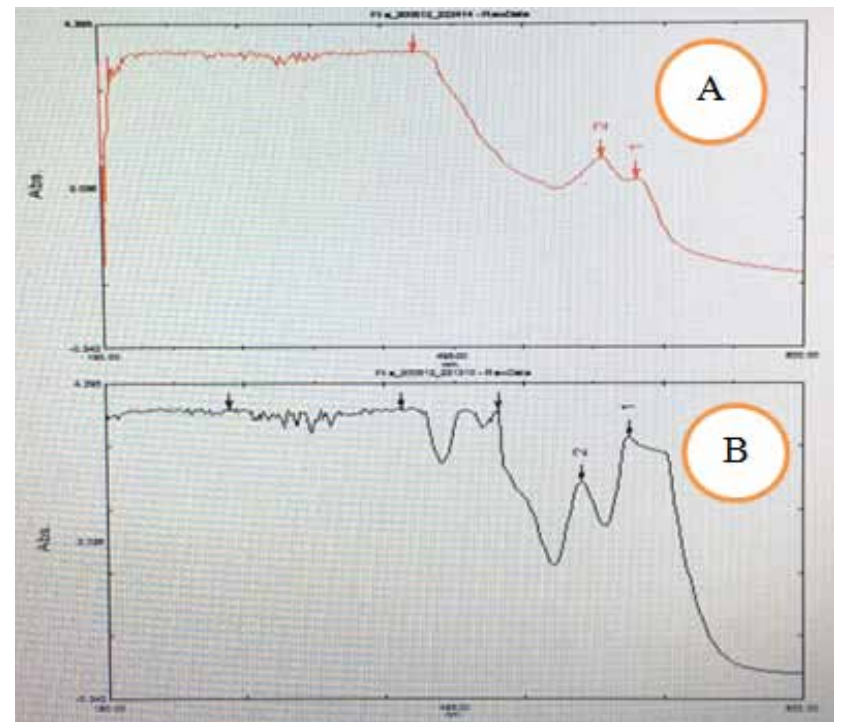

Figure 2. UV-vis spectra showing absorption of

(a) Natural petroleum ether extract (b) nanoscale petroleum ether extract

3- Fourier Transform Infra-Red (FTIR) of $G$. aparine extracts: The extract petroleum ether contained the highest antioxidants and was the best standard for nano (64.66) and therefore it was tested for this examination. Results of the FTIR spectra of the petroleum ether and aqueous extract of $G$. aparine revealed the presence of different functional groups such as phenolic- $\mathrm{OH}$ group stretching, Aromatic $\mathrm{C}=\mathrm{C}$, (Table 2). shows the infrared spectra for the petroleum ether and aqueous $G$. aparine extract .

Table (2): The IR Frequencies region for the functional groups of petroleum ether and aqueous of G. aparine extracts

\begin{tabular}{|c|c|c|c|}
\hline $\begin{array}{c}\text { I.R. } \\
\begin{array}{c}\text { Frequencies } \\
\text { of Aqueous } \\
\text { fraction }\end{array}\end{array}$ & $\begin{array}{c}\text { I.R. } \\
\text { Frequencies } \\
\text { of petroleum } \\
\text { ether fraction }\end{array}$ & $\begin{array}{c}\text { I.R } \\
\text { Frequencies } \\
\text { Standard } \\
\text { Groups (cm-1) }\end{array}$ & $\begin{array}{c}\text { The } \\
\text { Functional } \\
\text { Groups }\end{array}$ \\
\hline 3335.81 & 3380.17 & $3650-2500$ & $\begin{array}{c}\text { Phenolic- } \\
\text { OH group } \\
\text { stretching }\end{array}$ \\
\hline 1632.61 & 1642.46 & $1680-1620$ & $\begin{array}{c}\text { Aromatic } \\
\text { C=C }\end{array}$ \\
\hline
\end{tabular}

Viability assay (MTT): Cytotoxicity results of A375 cell viability after 48 hours of treated with various concentrations of petroleum ether fraction (6.250 to 400 $\mu \mathrm{g} / \mathrm{mL})$. Petroleum ether fraction resulted in a decrease in cell viability in a dose-dependent manner, and the nano petroleum ether of G.aparnie extract solution resulted in a significant decrease in the survival rate of A375 cells in dose dependence $(\mathrm{P}<0.0001)$ and $75 \%$ cell death rate at $400 \mu \mathrm{g} / \mathrm{mL}$, while IC50 was at77.03 $\mu \mathrm{g} / \mathrm{mL}$ and the petroleum ether extract was significantly higher IC50 at $116.5 \mu \mathrm{g} / \mathrm{mL}$ Figure (3) (A,B).

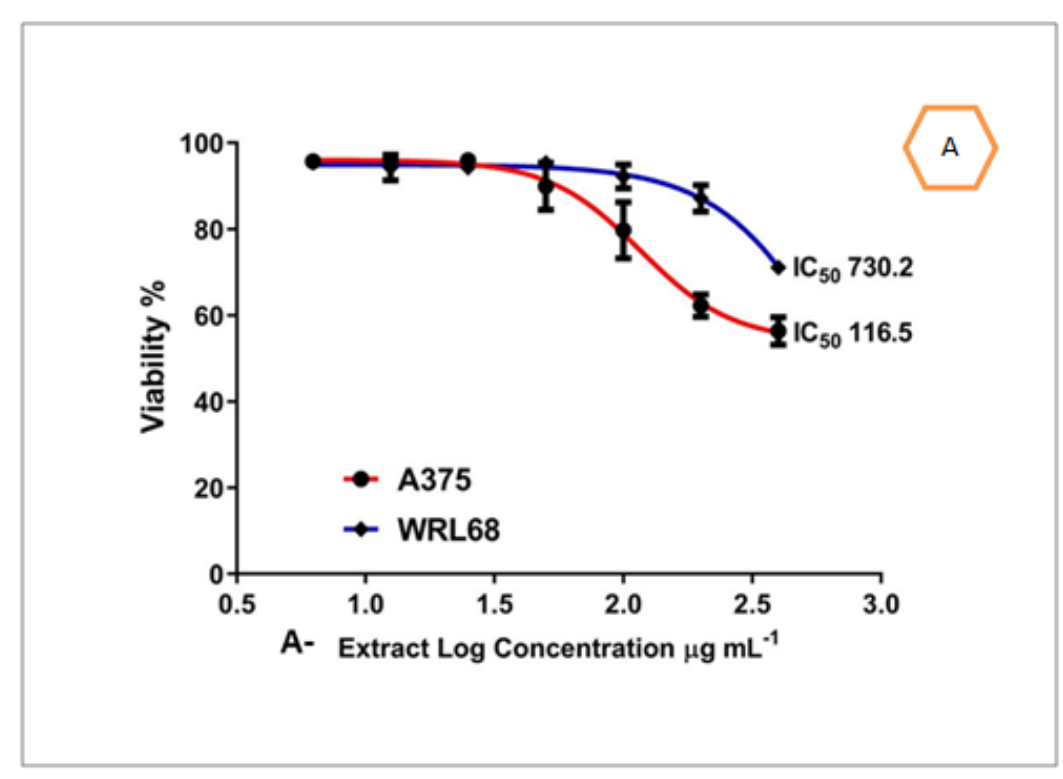




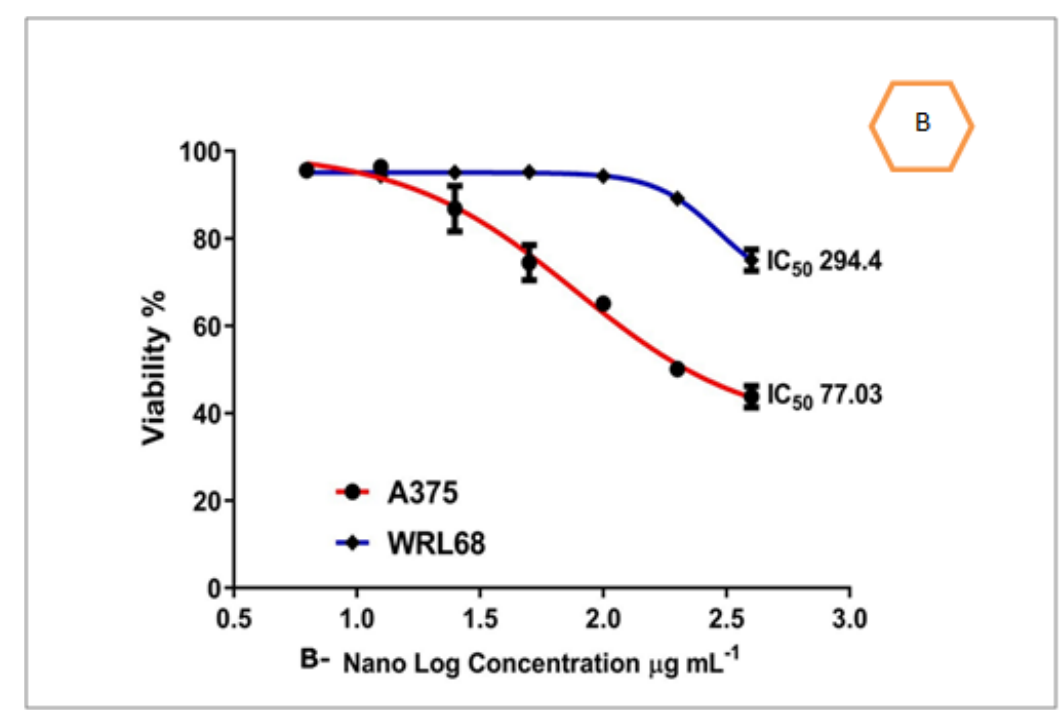
Figure 3: Cytotoxicity of petroleum ether fraction of G.aparine (A) and nano solution (B) with A375 and
normal cell WRL68.

For normal cell line WRL-68 the same figure shows that petroleum ether fraction shows weak and moderate cytotoxicity on normal cell line WRL-68 and the IC50 $730.2 \mu \mathrm{g} / \mathrm{m}$, while less Cytotoxicity with IC50 at $294.4 \mu \mathrm{g} / \mathrm{mL}$ for AgNPs. These results indicate potent Cytotoxicity and antitumor activity of petroleum ether extract, AgNPsits potential as an anticancer agent. Based on the results obtained from the Cytotoxicity assay,G.aparine petroleum ether AgNPs is the most potent extract in A375 and might suppress cancer cell proliferation or induce cancer cell undergoing apoptosis that lead to cell growth-inhibition.

\section{Conclusions}

It has indicated several areas for further research which are necessary to support the data presented here: AgNPs have been successfully synthesized using $G$. aparine extract; the nanoparticles have shown good anticancer activity towards human skin cancer cells. Synthesis nanoparticles method is easy, eco-friendly and efficient in developing different multifunctional nanoparticles which could be useful in environmental and nanomedicine applications.

Ethical Clearance: The Research Ethical

Committee at scientific research by ethical approval ofOmar Hasnawi HamdiShurook M.K. Saadedin and Iqbal Harbi in Iraq

\section{Conflict of Interest: Non}

Funding: Self-funding

\section{References}

1. Vlase, L., Benedec, D., Hanganu, D, et al: Evaluation of antioxidant and antimicrobial activities and phenolic profile for Hyssopus officinalis, Ocimumbasilicum and Teucrium chamaedrys. Molecules. 2014;19: 5490-5507.

2. Breitbart, EW, Greinert R, Volkmer B:Effectiveness of information campaigns. Prog Biophys Mol Biol .2006; 92: 167- 172 .

3. Suárez B, López-Abente G, Martínez C: Occupation and skin cancer: the results of the HELIOS-I multicenter case-control study. BMC Public Health.2007; 7: 180.

4. Gleiter, H. :Nanostructured Materials: Basic Concepts and and Microstructure. Acta Materialia.2000; 48: 1-12.

5. Boisseau, P.andLoubaton, B.: Nanomedicine, nanotechnology in medicine. ComptesRendus Physique.2011; 12(7), 620-636.

6. Wijnhoven, S. W., Peijnenburg, W. J., Herberts, et al: Nano-silver-a review of available data and knowledge gaps in human and environmental risk assessment. Nanotoxicology.2009; 3(2), 109-138.

7. Ozaki, J. I. R. O., Nakagawa, Y., Sakurai, G, et al: Recalcitrant chronic adhesive capsulitis of the shoulder. Role of contracture of the coracohumeral ligament and rotator interval in pathogenesis and 
treatment. The Journal of bone and joint surgery. American volume. 1989; 71(10), 1511-1515.

8. Awwad, A. M.; Salem, N. M. and Abdeen, A.O,: Biosynthesis of silver nanoparticles using Olea europaea leaves extract and its antibacterial activity. Nanoscience and Nanotechnology. 2012; 2(6):164170.

9. Prasad, K.S.; Pathak, D. and Patel, A: Biogenic synthesis of silver nanoparticles using Nicotianatobaccumleaf extract and study of their antimicrobial effect. African Journal of Biotechnology. 2011; 10 (41): 8122- 8130.

10. Kanipandian, N., Kannan, S., Ramesh, R, et al: Characterization, antioxidant and cytotoxicity evaluation of green synthesized silver nanoparticles using Cleistanthuscollinus extract as surface modifier. Materials Research Bulletin. 2014;49, 494-502.

11. Luis, M.; Hilda, A.; Alfredo, V, et al: Biosynthesis of Silver Nanoparticles Using Chenopodiumambrosioides. Journal of Nanomaterials, vol. 2014; 9

12. Dzimitrowicz A, Berent S, Motyka A, et al: Comparison of the characteristics of gold nanoparticles synthesized using aqueous plant extracts and natural plant essential oils of Eucalyptus globulus and Rosmarinus officials. Arabian Journal of Chemistry. http://dx.doi. org/10.1016/j.arabjc.2020.09.007.
13. MosmannT : Rapid colorimetric assay for cellular growth and survival: application to proliferation and cytotoxicity assays. J Immunol Method. 1983; 65(1-2): 55-63.

14. Thombre, R.S.; Mehta, S.; Mohite, J, et al: Synthesis of silver nanoparticles and its cytotoxic effect on THP-1 cancer cell line. International Journal of Pharma and Biosciences. 2013; 4(1):184-192

15. Krithiga, N.; Rajalakshmi, A. and Jayachitra, A : Green syntheses of silver nanoparticles using leaf extracts of Clitoriaternateaand Solanum nigrum and study its antibacterial effect against common nosocomial pathogens. Journal of Nanoscience. 2015; Article ID 928204, 8 pages. Hindawi Publishing Corporation.

16. Burris, J. N. :Nanocomposite Adhesive of English ivy (Hedera helix): Bioproduction, Nanoparticle Isolation, and Molecular Analysis. 2016;21-270

17. Omar,H :Anticancer And Antioxidant Activity of Silver Nanoparticles Produced From Galium Aparine extract. University of Baghdad.2020

18. Ahmad, N., Sharma, S., Singh, V. N, et al: Biosynthesis of silver nanoparticles from Desmodiumtriflorum: a novel approach towards weed utilization. Biotechnology Research International. 2011; 65(1-2): 55-63. 